\title{
A Modernidade Sincopada: moda de viola e o êxodo rural no Brasil
}

Jean Carlo Fautsino ${ }^{1}$

Desde os tempos de Mário de Andrade, na primeira metade do século XX, que a sincopa é tida como uma das especificidades da música popular brasileira.

De fato, alguns musicólogos viram na síncope uma característica definidora não apenas do samba, mas da música popular brasileira em geral. O mesmo Mário de Andrade afirma que a "síncopa... no primeiro tempo do dois por quatro" é a "característica mais positiva da rítmica brasileira". Também Andrade Muricy, num artigo sobre Ernesto Nazareth, lamenta os "finos artistas [que] estão com o senso rítmico viciado pelos ritmos regulares, e impossibilitados de reproduzirem com segurança e precisão um ritmo brasileiro característico, o ritmo sincopado".(Sandroni, 2012)

Uma definição bastante elucidativa e precisa do que vem a ser a sincopa foi originalmente cunhada (talvez para surpresa dos sociólogos) por Jean-Jacques Rousseau sendo parte do seu Dictionnaire de Musique que originalmente correspondia às suas contribuições para o projeto Enciclopédico de Diderot (Gumboski, 2012). O verbete do autor que escreveu o famoso Contrato Social, citado no artigo A Memória e o valor da sincope (Freitas, 2010), define a sincopa da seguinte maneira:

\footnotetext{
${ }^{1}$ Visiting Research Associate at the Department of Spanish, Portuguese and Latin American Studies, within the Faculty of Arts and Humanities at King's College London since April 2015. PhD in Sociology from UFSCar, MA and BA and from UNICAMP. Work at Brazilian National Research Education Network (NREN) since 1998.
} 
Síncope é a prolongação sobre o tempo forte de um som começado em tempo fraco; assim toda nota sincopada está em contratempo, e toda sucessão de notas sincopadas é uma marcha em contratempo. [...] A síncope tem seus usos na melodia para a expressão e o goût $d u$ chant; contudo sua principal utilidade está na harmonia para a prática das dissonâncias. (Rousseau apud Freitas, 2010).

No contexto da música popular brasileira, no entanto, o conceito tem uma complexidade própria cujos detalhes e nuances foram tratados por Carlos Sandroni no livro Feitiço Decente. Das reflexões feitas pelo autor, importa-nos aqui a maneira como sua ocorrência é percebida como um "desvio na ordem normal do discurso musical" quebrando sua regularidade e, por isso, indo contra a expectativa do ouvinte (Sandroni, 2012). Segundo se deduz desta perspectiva, haveria então certa similaridade entre esta especificidade da música popular brasileira com a própria história desta sociedade cheia de "desvios e irregularidades" na sua ordem normal gerando, não raro, fatos inesperados que surpreendem o espectador. Esta é, em suma, a hipótese a ser desenvolvida ao longo deste artigo.

A hipótese será desenvolvida a partir de uma releitura da minha pesquisa de doutorado, recentemente concluída, sobre o desenvolvimento da modernidade no estado de São Paulo no século XX. O objetivo da pesquisa foi o de compreender o chamado êxodo rural brasileiro, a partir da análise das letras das modas de viola, gravadas pela dupla Tião Carreiro e Pardinho, ao longo da sua carreira em um período que corresponde também às décadas em que houve a grande mudança demográfica que levou o Brasil a se tornar uma nação predominantemente urbana. O enfoque da análise esteve centrado nos temas que revelam o encontro da cultura caipira com a 
modernidade e o consequente esforço de elaborar uma conciliação entre essas diferentes culturas.

A moda de viola corresponde a um dos subgêneros da chamada música caipira de raiz que tinha como público alvo os camponeses da região geográfica compreendida por São Paulo e seus estados vizinhos, embora esta definição seja meramente ilustrativa e imprecisa dado que não há potencialmente limites geográficos para o alcance da música. A moda de viola - e não outro subgênero da música caipira - foi escolhida como recorte da minha pesquisa de doutorado devido à legitimidade étnica que ela possui junto ao público como revela a pesquisa de Allan de Paula Oliveira:

A moda-de-viola é um outro gênero praticado e valorizado pelos violeiros piracicabanos. É tida, por vários deles, como o exemplo da "verdadeira música caipira", e sempre que eles querem se referir ao que não é música caipira ou sertanejo-raiz, eles citam duplas midiáticas que não cantam modas-de-viola. (Oliveira, 2004, p. 127)

Conforme observou Rafael Garcia, autor de uma dissertação de mestrado sobre a estética da moda de viola, a sincopa não é uma obrigatoriedade neste gênero musica embora ela esteja presente em algumas de suas composições: mais precisamente em algumas de suas introduções onde se toca um ritmo conhecido como "pagode-de-viola", cuja invenção foi atribuída ao violeiro Tião Carreiro.

No pagode-de-viola, enquanto a viola caipira realiza os ponteados, o violão realiza um ritmo denominado cipó-preto, cuja rítmica é marcada pelo contratempo. Tanto as proposições rítmicas do solo ponteado na viola caipira quanto do acompanhamento feito pelo violão são 
marcadamente sincopadas. Este é o mesmo conceito de contrametricidade de que falam José Miguel Wisnik e Carlos Sandroni. Esta característica rítmica sincopada, tão presente na música popular brasileira, é a base essencial do pagode-caipira. Desta forma, podemos dizer que temos como gêneros “opostos" ritmicamente o pagode-deviola e a moda-de-viola. Contudo, em inúmeras modas-de-viola se fazem presentes as síncopes contramétricas do pagode-caipira. (Garcia, 2011, p. 163)

Porém, segundo se depreende da análise de Garcia, a maior irregularidade da moda de viola não se encontra neste pagode que é tocado na sua introdução, mas, sim, naquilo que é sua essência: no seu canto recitativo que é entoado sem um pulso regular bem definido apesar de amparado por uma melodia específica. Esta particularidade leva, por sua vez, a existência de um "pulso oscilante dos cantadores" e à uma subdivisão imprecisa das frases musicais (Garcia, 2011, p. 144-145).

Como vemos nas músicas selecionadas para transcrições e análises, apesar de se apresentar como um canto recitativo, algumas modas-deviola podem ser enquadradas em fórmulas de compasso específicas, embora estejam sempre respeitando as prerrogativas apresentadas. Nestes casos, podemos afirmar a existência de um pulso e subdivisão sugeridos dentro de uma fórmula de compasso definida, mas desprezada, onde as oscilações métricas, que nos obrigam literalmente a "dançar conforme a música", quando transcritas para o papel, são facilmente identificadas através da constante utilização de fermatas. Porém, algumas músicas obedecem claramente um pulso e uma métrica 
tão inconstante que a escrita tradicional com fórmulas de compasso determinadas dificilmente dá conta de registrar, mesmo com compassos híbridos. (Garcia, 2011, p. 146)

Entretanto, a despeito das dificuldades e imprecisões na transcrição das modas de viola para uma partitura musical, Rafael Garcia se dedicou a isso durante seu mestrado. Algumas das modas de viola que ele transcreveu foram, inclusive, analisadas na minha tese de doutorado - embora sob uma diferente ênfase e propósito. Vale ressaltar que a coincidência na escolha das modas deve-se, sobretudo, ao lugar de destaque e referência que as modas da Tião Carreiro e Pardinho ocupam neste gênero musical como prova a dissertação de mestrado Moda de viola e modos de vida de Eduardo Menezes que também escolheu, para análise, modas de viola da mesma dupla. Entretanto, se há coincidência na escolha de algumas modas, a análise das irregularidades musicais difere-se consideravelmente entre os dois trabalhos. Assim, enquanto Rafael Garcia analisa essas irregularidades na estética propriamente das modas de viola, Menezes as analisa sob o ponto de vista das letras dessas modas que expressam o que se pode chamar de tentativa de conciliar a tradição com a modernidade.

Por que esta conciliação era importante para o público ouvinte dessas modas? Por uma questão de sobrevivência física e identitária, já que a ascensão da modernidade traz consigo um imperativo de adaptação. Assim, ou o camponês incorporava seus códigos e valores específicos ou estaria fadado à mesma decadência pela qual sua comunidade tradicional já estava passando no período. A primeira dessas adaptações, no contexto analisado, era o êxodo para a cidade. Por isso, o êxodo foi o recorte da minha pesquisa de doutorado que recebeu o título de $O$ Êxodo Cantado.

No entanto, o êxodo era apenas o efeito, isto é, a aparência do que eu realmente desejava estudar e compreender: os dilemas e tensões próprios deste processo de 
adaptação cultural. E dado que a música é, como a arte em geral, um local privilegiado para expressão e consequente compreensão dessas questões (Williams, 1979) este foi o ponto de partida da minha análise.

De fato, como veremos a seguir, as tentativas de conciliação da cultura caipira com a modernidade trouxeram alguns benefícios como, por exemplo, o registro desta forma tradicional de expressão cultural e sua divulgação mais ampla como costuma acontecer no cenário da reprodutibilidade técnica (Benjamin, 1996). Porém, mais que isso, como já foi evidenciado pela recente tese de doutorado de Ivan Vilela, a divulgação dessas músicas através do rádio operou como um "fator aglutinante e re-enraizante dos valores de vida do camponês caipira, agora urbano" (Pinto, 2011, p. 249) ajudando-lhe, portanto, a preservar a sensação de pertencimento a algo que muitas vezes já não mais existia do ponto de vista material. Contudo, a adaptação cultural do camponês à modernidade não interessava apenas ao camponês que migrou para a cidade. Ela interessava também ao sistema capitalista em ascensão que, como sabemos por Weber, requer que os indivíduos tenham uma ética do trabalho que "não é produto da natureza":

Ao contrário, o trabalho deve ser executado como se fosse um fim absoluto em si mesmo, como uma vocação. Contudo, tal atitude não é produto da natureza. Não pode ser estimulada apenas por baixos ou altos salários, mas só pode ser produzida por um longo e árduo processo educativo. (Weber, 2001, p. 57)

E este "longo e árduo processo" de formação e educação do camponês para viver no capitalismo foi justamente o que procurei analisar através das modas de viola da dupla Tião Carreiro e Pardinho. Um aspecto não de todo desprezível para compreensão do desenvolvimento do capitalismo já que, ainda segundo Weber, a formação deste novo 
espírito do capitalismo ou deste ethos específico para o desenvolvimento deste sistema econômico é mais importante do que a quantidade de dinheiro investido na indústria:

E o que é mais importante nessa relação, o que trouxe essa revolução, em tais casos, não foi geralmente o fluxo de dinheiro novo investido na indústria - em muitos casos que conheço, todo o processo revolucionário foi acionado por poucos milhares de capital emprestado de conhecidos - mas foi o novo espírito, o espírito do moderno capitalismo que fez o trabalho. (Weber, 2001, p. 57)

No entanto, a exemplo dos ritmos sincopados nacionais, o resultado desta formação do caipira foi surpreendente havendo não só irregularidades no processo de desenvolvimento da modernidade em si como no próprio discurso das narrativas das modas que, a princípio, parecia sustentar a criação deste ethos específico através de um esforço de conciliação entre o tradicional e o moderno, mas, que não se limitou a isto. Como veremos no tópico seguinte, se houve, por um lado, modas que apresentaram casos bem sucedidos desta conciliação, por outro lado, houve composições que mostraram justamente o contrário apontando os limites, as insuficiências e as armadilhas das promessas do sistema econômico em ascensão.

\section{A moda sincopada}

Tião Carreiro e Pardinho foi a dupla que mais se notabilizou nas interpretações das modas de viola no período histórico a que me dediquei na minha tese de doutorado e que corresponde às décadas de 1960, 1970 e 1980.

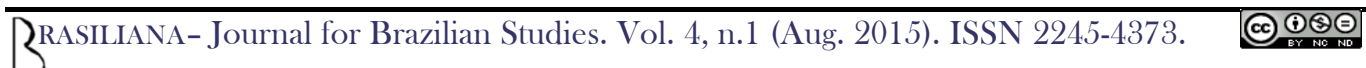


Portanto, quando me refiro às modas de viola do período estudado, não estou falando daquelas músicas compostas para um pequeno público em comunidades rurais isoladas, mas de músicas que, apesar de manterem-se fieis à estética da origem rural, eram produzidas e distribuídas pela indústria cultural então em desenvolvimento no Brasil.

Como, no entanto, a gravação, a distribuição e mesmo o sucesso deste tipo de música - vinculada a um estilo de vida que estava sendo desmontado pela modernidade - era possível de se realizar dentro deste contexto? Uma das explicações é que, segundo se deduz da análise de Renato Ortiz (1985), o governo militar que então se instaurara no país após 1964 entendia (ou assim entendeu durante algum tempo) que a preservação da cultura nacional era uma questão ligada à segurança nacional merecendo, portanto, investimento e incentivo.

Eis, portanto, uma espécie de sincopa na própria história da indústria cultural que teria contribuído, ao menos durante este período, para o sucesso da música caipira e consequentemente da moda de viola. Mas, o sucesso na indústria cultural não leva necessariamente à preservação da essência de um gênero musical nem tampouco do significado que ele tinha originalmente antes do advento desta indústria como analisou Walter Benjamin ao dizer que, na era da reprodutibilidade técnica, a obra de arte perde sua aura:

Em suma, o que é a aura? É uma figura singular, composta de elementos espaciais e temporais: a aparição única de uma coisa distante por mais perto que ela esteja. Observar, em repouso, numa tarde de verão, uma cadeia de montanhas no horizonte, ou um galho, que projeta sua sombra sobre nós, significa respirar a aura dessas montanhas, desse galho. (Benjamin, 1994, p. 170).

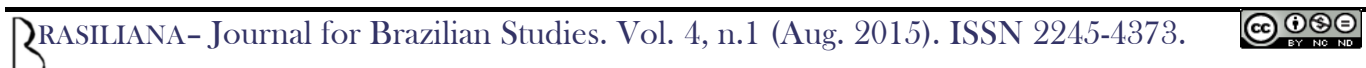


No entanto, não se pode dizer que a aura é completamente perdida na modernidade. É verdade que ela deixa de existir como uma experiência coletiva e prolongada. Mas, ao menos no período histórico em que essas modas de viola faziam sucesso era ainda possível alcançar a compreensão do significado desta aura (ainda que de maneira individual) através da audição dessas músicas que possuem o poder de transplantar ou elevar o ouvinte para outra realidade.

Uma experiência análoga pode ser obtida ainda hoje se dedicarmos nossa atenção totalmente à audição dessas modas como quem aprecia uma obra de arte. Nessas condições, durante três minutos somos conduzidos para dentro de histórias envolvendo bois, boiadas, peões boiadeiros, lavradores, violeiros e outros personagens e cenários típicos do meio rural para acompanharmos com certo suspense e apreensão o desfecho de suas aventuras.

Esta transcendência era conferida pelo poder da narrativa que, no entanto, tendia a desaparecer também em decorrência do desenvolvimento da modernidade. Mas, no período em questão, pode-se dizer que a arte de narrar através das modas de viola teve uma espécie de último suspiro. Algo, inclusive, coerente com momento épico pelo qual passava as comunidades rurais cujo estilo de vida estava se desfazendo. E para estudar essas narrativas nas modas de viola, fiz um recorte escolhendo as interpretações feitas pela dupla Tião Carreiro e Pardinho.

Tal escolha guiou-se tanto pela notoriedade e reconhecimento de público da dupla como um dos maiores interpretes da moda de viola quanto pela particularidade de suas narrativas apresentarem, ao menos aparentemente, uma perspectiva positiva na adaptação do camponês à cultura do meio urbano. Algo que destoa, por exemplo, de outras músicas da mais famosa dupla caipira (Tonico e Tinoco), as quais normalmente lamentam uma espécie de idade de ouro perdida no passado ecoando, assim, o saudosismo transfigurador que Antônio Candido observou no seu trabalho de campo: 
Em primeiro lugar, observamos o que se poderia qualificar de saudosismo transfigurador - uma verdadeira utopia retrospectiva, se coubesse a expressão contraditória. [...] Consiste em comparar, a todo propósito, as atuais condições de vida com as antigas; as modernas relações humanas com as do passado. As primeiras, que interessam diretamente a este trabalho, referem-se principalmente a três tópicos: abundância, solidariedade, sabedoria. (Candido, 1977, p. 193-194)

O primeiro conjunto de quatro modas que analisei em profundidade na minha tese, inclusive, reforçam este aspecto positivo ou, dito de outra forma, os casos de sucesso deste processo de adaptação cultural. A primeira moda deste primeiro conjunto chamase Derrota do Boi Palácio. Sua narrativa conta de maneira condensada a trajetória de um peão até então anônimo que, mesmo sem renome, consegue montar num touro dentro dos torneios das festas de peão que no período histórico equivalente se institucionalizou ampliando cada vez mais sua abrangência integrando-se, inclusive, aos circuitos internacionais deste tipo de evento (Pimentel, 1997) que ainda hoje fazem sucesso.

Ele montou e não caiu naquele boi afamado

Gumercindo pra revanche, logo ele foi convidado

No dia cinco de junho, no grande dia esperado

Tornou montar e não caiu, onde foi considerado

Que o malvado do mulato tem de ser mesmo de fato o melhor peão do estado 
O fato de ser um peão de origem humilde que sai do anonimato e se torna campeão criando uma perspectiva de carreira promissora dentro desta indústria de entretenimento é uma evidente alegoria das promessas do sistema capitalista sintetizados no estereótipo do self-made man que através desta narrativa se adequa à representação simbólica do público ouvinte na figura deste peão anônimo e humilde financeiramente como eram milhões de camponeses que viviam o êxodo naquele momento.

Na segunda moda analisada, Boiadeiro Punho de Aço, a mesma perspectiva do selfmade man volta a aparecer nesta narrativa que é centrada no mesmo personagem típico do universo rural: o peão boiadeiro. Nesta narrativa, no entanto, ele não é um peão anônimo. Embora seu nome não seja dito em momento algum, a moda descreve em detalhes a educação esmerada, tanto do ponto de vista técnico quanto moral que ele recebeu do próprio pai para se tornar boiadeiro. Ao completar dezoito anos, ele então deixa a fazenda da família para desbravar o mundo na profissão de boiadeiro, na qual ele será, a propósito, bem-sucedido ganhando muito dinheiro.

Por este Brasil afora fiz como faz as nuvens no espaço

Vaguei ao léo conhecendo terras, sempre ganhando dinheiro aos maço

Meu cipó ${ }^{2}$ em três rodía cobria a anca do meu picaço ${ }^{3}$

Foi o que me garantiu o nome de boiadeiro punho de aço

A narrativa acaba tendo um desfecho grandioso, no qual o jovem boiadeiro salva a vida do pai julgando que estava salvando um anônimo que precisava de ajuda. Seu gesto

\footnotetext{
${ }^{2}$ Cipó aqui corresponde ao laço de boiadeiro.

${ }^{3}$ Picaço faz alusão ao tipo de pelagem de cavalo que, neste caso, corresponde à uma base preta com partes brancas pontuais como, por exemplo, uma mancha na cabeça ou na pata.
} 
com o anônimo sugere o sucesso da educação moral que seu pai havia lhe dado e, assim, a proposta de conciliação entre tradição e modernidade se realiza magistralmente ao mostrar que uma formação tradicional era perfeitamente compatível com o novo contexto econômico no qual se podia não só ter sucesso profissional como também condições financeiras para ajudar os pais mais tarde realizando, assim, a gratidão de filho.

Na moda seguinte, Mineiro do Pé Quente, a mesma perspectiva de sucesso na tentativa de conciliação dos valores irá se repetir. Desta vez, num personagem que representa a figura tradicional de lavrador ou, para ser mais especifico, de um trabalhador rural que migrou para a cidade e que, passo a passo, a partir do nada e com o esforço disciplinado e árduo na linha da ideologia do self-made man tornando-se um grande e honrado empresário capitalista totalmente alinhado ao sistema. No entanto, seu sucesso econômico significa, acima de tudo, uma vitória moral contra as ameaças à dignidade que a corrente da vida traz ao homem correspondendo, por isso, à uma conciliação da modernidade como os valores tradicionais.

O mineiro está lá em cima lutando honestamente

Dono de uma grande empresa dá emprego a muita gente

Sendo ele o grande esteio diretor e presidente

Falo a verdade e não minto: senhor Augusto Alves Pinto é um mineiro do pé quente

Sua vida é um livro aberto que nem o tempo consome

Mostrou pra filho e parente que vencer honestamente não é impossível pro homem 
Já na moda Minha Vida, vemos o mito do self-made man aplicado à figura do violeiro que também migrou para a cidade e alcançou razoável sucesso na profissão vindo de uma origem humilde e atuando de forma disciplinada e contínua na sua profissão pois ainda que ele diga que tocar a viola é fácil, isto parece, na verdade, indicar sua vocação pela profissão já que ele toma vários cuidados ao compor diferentes modas para diferentes públicos e ocasiões além dos cuidados com a voz. Como se vê no trecho a seguir, ele diz também que isto lhe traz dinheiro com facilidade: O sucesso na nova economia, obtido por intermédio de uma ocupação tão cara à cultura caipira como a de violeiro (tocador de viola), sugere claramente mais uma pretensa conciliação entre tradição e modernidade.

Tive grande impulso

Com outro recurso

A viola é tão fácil

É só mexer nos traço

Fazer modas boa

Quando o povo enjoa

Fazer modas dobrada

E bem selecionada

$\mathrm{Pr}^{\prime}$ as festas que for

Não passar calor

Evitar de beber

Pra voz não perder

Dinheiro no bolso

Vem com pouco esforço 
Neste meu céu de anil

Divertindo o Brasil"

Além da evidente influência da ideologia do self-made man como uma espécie de leitmotio nessas narrativas, outra particularidade comum a elas é a mobilidade e o deslocamento que evidenciam o movimento do êxodo rural que vinha se adensando na época. Mas, conforme já mencionamos aqui, esses aparentes casos de sucesso encontraram sua sincopa, isto é, sua irregularidade temática dentro do próprio universo composto pelo conjunto das modas de viola gravadas pela mesma dupla sendo este justamente o foco da análise que se seguiu a este primeiro conjunto de quatro modas.

No segundo conjunto composto por outras quatro modas que foram analisadas e que se assemelham a estas não só pela centralidade dos personagens de origem rural como também pela presença da noção de deslocamento como representação e as vezes até mesmo como referência explicita ao êxodo, a proposta de conciliação entre tradição e modernidade expressa na incorporação do ethos do self-made man começa a apresentar um resultado surpreendente para o ouvinte revelando o outro lado da realidade social da época.

A primeira moda do segundo grupo foi analisada na minha tese de doutorado chama-se Pousada de Boiadeiro. Apesar de ter o nome de boiadeiro no título, o protagonista da narrativa é um violeiro que, a exemplo dos outros protagonistas das modas anteriores, migrou para a cidade. No meio urbano, ele alcançou sucesso como músico profissional. No entanto, ele adia indefinidamente uma visita à sua terra natal no meio rural ao que tudo indica para não se deparar com um cenário de decadência social, cultural e material que ali se instaurou. Eis, portanto, uma evidente perda gerada pela ascensão da modernidade mesmo para aqueles que alcançaram o sucesso econômico e profissional: a perda do seu universo social e cultural de origem. 
Esse tempo já vai bem distante, tudo, tudo na vida mudou O piquete das vacas leiteiras cobriu-se de mato e, enfim, se acabou Os parentes mudaram de rumo, ninguém sabe também onde estou Despedi-me numa madrugada, seguindo a estrada que Deus me traçou

A moda seguinte, Herói Sem Medalha, tem como protagonista da sua narrativa um lavrador que teve que migrar para a cidade de maneira involuntária em reposta ás "forças invisíveis" que influem sobre o destino do homem e mudam sua sorte. Apesar de ter trabalhado em prol do progresso no passado, a sociedade que ele ajudou a construir com a força do seu trabalho não lhe deu o reconhecimento devido inviabilizando sua vida no campo e empurrando-o para a cidade onde ele é relegado a uma posição de marginalidade na qual tem que lutar para manter sua dignidade que, ao final, é conquistada a duras penas. A narrativa e seu desfecho, portanto, revela quão frágeis e excludentes eram as promessas da modernidade e consequentemente do desenvolvimento do capitalismo tal qual se configurava na época.

Veja bem a nossa vida domo muda de repente

Eu que às vezes chorava quando um boi ficava doente

Alí eu era obrigado a matar a rês inocente

Mas, certo dia o destino me transformou novamente

O boi de cor de carvão, pra morrer nas minhas mãos, estava na minha frente"

A terceira moda deste conjunto, Velho Peão, retoma novamente a figura tradicional do peão boiadeiro. A exemplo do protagonista da moda anterior, o personagem desta 
moda também irá descobrir que a incorporação que ele fizera do ethos do self-made man seria insuficiente para garantir seu sucesso financeiro e nem ao menos uma vida digna na nova economia. Apanhado subitamente por uma doença que não é nomeada na narrativa, mas que reforça a característica de fragilidade física da velhice, o protagonista da história, que já foi "o rei dos peões", isto é, o líder de comitivas de boiadeiros se vê numa posição de indignidade declarada devido ao incômodo que sua presença como hóspede na casa do filho gera:

Pobre de quem nesta vida na velhice não pensô

Ao me ver velho e doente, um filho me amparô

Recebo tanta indireta da nora que não gostô

E meu netinho inocente, chorando já me falô:

A mamãe já deu estrilo, diz: "aqui não é asilo",

mas eu gosto do senhô

O que faltou à formação deste self-made man que já havia alcançado sucesso, no passado, a partir de uma conduta ascética e disciplinada? A improvidência para o futuro, talvez, que se traduz na necessidade de uma poupança ou na aquisição de bens duradouros que lhe pudessem garantir uma independência financeira na velhice. Porém, tão importante quanto esses limites e deficiências no processo de adaptação aos valores da racionalidade moderna são as tensões nas relações sociais que esta narrativa revela como, por exemplo, a dificuldade que os trabalhadores autônomos do meio rural tinham para obter aposentadoria e os potenciais conflitos entre as gerações no processo de adaptação à cultura urbana como foi observado nas pesquisas que Eunice Durham (1973, p. 204) realizou na época com migrantes que mudaram do campo para a cidade de São Paulo. 
Por fim, a última moda de viola analisada em profundidade na minha tese de doutorado chama-se Boi Sete Ouro. Sua narrativa dialoga com a primeira moda analisada e aqui mencionada, Derrota do Boi Palácio, devido a representação simbólica do boi e sua centralidade para a narrativa. E a exemplo da outra moda, o protagonista desta narrativa alcança sucesso na indústria de torneio de festa de peão. No entanto, sendo ele um boi, ou seja, um animal cujo destino lhe é alienado assim como os meios de produção (Marx, 1996), seu sucesso tem como principal proveito o enriquecimento do seu dono que se gaba de ter um "trabalhador", por assim dizer, tão dedicado e talentoso.

Circo rodeio Ipiranga, sua fama vai avante

Faixa preta é o proprietário, tem um boi que lhe garante

O seu nome é Sete Ouro, seus pulos vale diamante

São Paulo, Goiás e Minas fez proeza importante

Parece que o tal boi tem sabão em cima do couro

Faixa Preta fala grosso: o bichão vale um tesouro

Derrubou seissentos peão, não contando os calouros

Deixo da vida de circo se quebrarem o Sete Ouro

Já o boi, devido à sua condição, nada mais ganha senão certo renome em decorrência da condição de ter se adaptado bem aos novos tempos. Eis aqui um retrato claro do que efetivamente representava a adaptação do camponês ao meio urbano e industrial: um animal domado, desterrado de sua cultura e meio de origem, condenado a um imperativo de sucesso obtido com base na competição com outros pobres coitados que sonham como um prêmio e reconhecimento que vem para poucos. 


\section{O Êxodo Sincopado}

Além da sincopa na estética da moda de viola e da sincopa temática presente nas suas narrativas, existe ainda o que poderíamos chamar da sincopa do processo histórico ao qual essas composições se integram e que, no contexto da referida tese de doutorado, encontra-se ligado ao êxodo rural brasileiro.

Estatisticamente, sabe-se que a grande mudança demográfica brasileira que fez com que o país deixasse de ser uma nação predominantemente rural para se tornar um país majoritariamente urbano aconteceu entre as décadas de 1960, 1970 e 1980. Mais precisamente, foi na década de 1970 que ocorreu a mudança como se pode ver pelo gráfico a seguir:

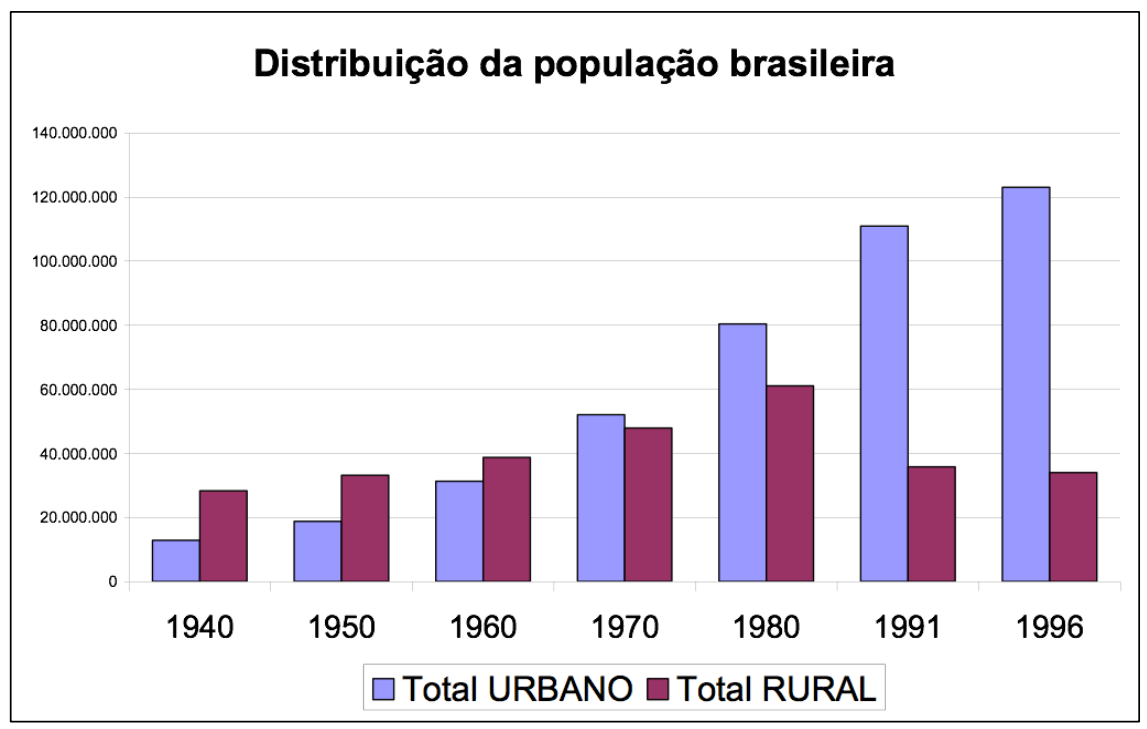

Gráfico 1: elaborado a partir de dados disponíveis em http://www.ibge.gov.br

No entanto, se fosse possível traduzir esses dados em linguagem musical haveria certamente uma sincopa a indicar simbolicamente que o movimento começou antes deste período. Nas décadas de 1940 e 1950, quando Antônio Candido realizou seu 
trabalho de campo em Bofete, no interior de São Paulo, ele já tinha observado este êxodo estrutural como caminho cada vez mais utilizado, pelos camponeses, para se resolver os dilemas pessoais de uma situação que já era de crise.

Os desajustes se resolvem, cada vez mais, pela migração urbana, com abandono das atividades agrícolas e passagem a outro universo da cultura. (Candido, 1977, p. 216)

Além disso, antes mesmo deste clássico trabalho de Antônio Candido, Os Parceiros do Rio Bonito, os primeiros estudos sociológicos sistemáticos sobre a população camponesa no estado de São Paulo já apontavam o êxodo para a cidade como um fato estrutural (Willems, 1947, p. 51-52). Assim, antes mesmo da mudança definitiva na configuração demográfica nacional que se operou na década de 1970, o êxodo já vinha acontecendo em menor proporção devido a mudanças na estrutura produtiva do campo que deixou de ser de subsistência para estar voltado para a agricultura exportadora gerando, consequentemente, uma dependência e criando a cultura das mercadorias que como sabemos pelos estudos de Marx (1996) está na gênese da economia capitalista.

Expressão dessas mudanças foi a Lei de Terras, criada ainda no século XIX para, fundamentalmente, deter o processo de apropriação livre da terra mediante a definição de um preço que tornaria sua aquisição inviável para os trabalhadores nacionais e imigrantes alcançassem autonomia deixando, assim, de trabalhar nas grandes fazendas da agricultura exportadora

É bastante conhecido o momento histórico da criação desta lei (a Lei de Terras). Fundamentalmente, ela surgiu para deter o processo de apropriação livre mediante a posse da terra. Era o momento da 
imigração de trabalhadores estrangeiros, cujo destino deveria ser, especialmente, o fornecimento de força de trabalho às lavouras de café. Por essa razão, o preço da terra estipulado pelo Estado deveria ser tal que sua compra se tornasse impossível aos trabalhadores nacionais e imigrantes. (Silva, M.1999, p. 30)

Já no século XX, o êxodo iria se adensar depois que o governo federal, preocupado com o aumento do fenômeno e com a potencial falta de alimentos, decide tomar medidas para refreá-lo (Stolcke, 1986, p. 138-139). Paradoxalmente, as medidas tomadas e que correspondem ao aumento da industrialização só fariam aumentar o êxodo porque, ao que tudo indica, o governo tomou o êxodo como causa sendo que ele era efeito de outra causa que não sendo tratada manteve-se. Segundo Verena Stolcke, isto aconteceu porque as análises sociais que subsidiaram a decisão de governo não consideraram a estrutura de produção ou a estrutura agrária do período (Stolcke, 1986, p. 141-142).

É por força do processo de industrialização do país, que a agricultura deixa de ser um setor "isolado" (no sentido de quase-autosuficinete) da economia para quase tornar parte integrante de um conjunto maior de atividades interrelacionadas. Portanto, pode-se dizer que é fundamentalmente a partir do período da industrialização pesada (1956/61) que se acelera o processo de industrialização da agricultura brasileira, embora São Paulo já houvesse iniciado sua modernização antes." (Silva, J. G., 1981, p. 68)

A transposição deste movimento histórico para uma hipotética partitura encontraria, no entanto, uma nova sincopa ou ao menos uma irregularidade capaz de surpreender o 
ouvinte ou analista menos atento. No início da década de 1960, o movimento do êxodo rural que se apresentaria cada vez mais irremediável, de repente sofre um refluxo e o caminho de volta para o meio rural iria se tornar simultaneamente realidade e objeto de desejo do camponês que havia migrado para a cidade.

A década de sessenta mostra uma redução das pequenas e médias explorações e um aumento das muito grandes. Mas, aparentemente de maneira contraditória com essa tendência de concentração, as explorações muito pequenas (de menos de 2 ha) são as que apresentam as maiores taxas de crescimento. Essa multiplicação das explorações muito pequenas, longe de ser um pretenso movimento de "recampesinização" da agricultura paulista, mostrou-se apenas como uma etapa do processo de expropriação dos pequenos e médios estabelecimentos, que se intensifica na primeira metade da década seguinte. (Silva, J. G., 1981, p. 70)

A possibilidade concreta de realizar este sonho de voltar para o campo está presente em muitas composições da música caipira da época e uma das modas de viola mais famosas que expressa este sonho que, de fato, se tornou realidade para alguns durante algum tempo chama-se Terra Roxa. Esta moda, que infelizmente não pôde ser analisada em profundidade na minha tese, narra a história de um camponês de origem humilde que, a partir de uma iniciativa individual, disciplinada e ascética em conformidade, portanto, com o ethos do self-made man conseguiu fazer uma plantação expressiva de café num "ranchinho" que ele comprou no estado do Paraná refletindo, assim, a política de colonização das novas terras que este estado vizinho a São Paulo vinha implementando na época: 
Estudos referentes ao vizinho Estado do Paraná sugerem que esses dois grandes movimentos sucessivos e contrários (a multiplicação dos pequenos estabelecimentos de produtores com formas precárias de acesso à terra na década de sessenta e sua posterior redução na primeira metade dos anos setenta) não é um fenômeno isolado do Estado de São Paulo. (Graziano da Silva, 1978; e Ipardes, 1976). (apud Silva, J. G., 1981, p. 72)

No entanto, após este breve período, a industrialização do campo retoma seu ritmo levando ao aumento da força mecânica que, por sua vez, gerou a redução no uso da mão de obra e sua consequente expulsão para o meio urbano. Em 1960, no estado de São Paulo, o total de estabelecimentos agropecuários que usavam o tipo de força mecânica era de 6,1\%, enquanto em 1970 este número tinha saltado para 25,6\% chegando em 1975, a 33,4\% (Silva, J. G., 1981, p. 107). E, de 1974 a 1978, o preço da terra em São Paulo, que na década anterior tinha se mantido relativamente constante, quadruplicou de valor (Silva, J. G., 1981, p. 80) colocando, assim, uma "pá de cal" no sonho, do camponês, de voltar para o meio rural sepultando, ao mesmo tempo, uma era.

Neste mesmo período, o número de trabalhadores residentes no meio rural reduziu-se a menos da metade, passando de 1.727 .000 em 1964 para 834.000 em 1975 (Silva, J. G., 1981, p. 122) levando a um êxodo de mais de 2,5 milhões de pessoas do campo paulista (Silva, M., 1998, p. 63). A partir de então, a nova realidade do trabalho no campo seria marcada pela proletarização, na qual o camponês ia ao meio rural apenas para trabalhar na condição de bóia-fria embora residisse nas periferias das cidades.

\section{A Modernidade Sincopada}

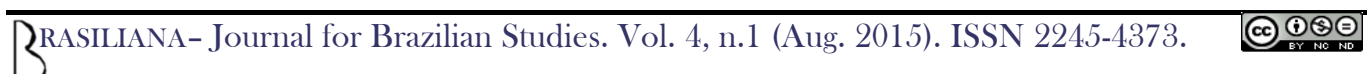


Como procurei apresentar até aqui, a sincopa esteve presente tanto na forma quanto no conteúdo das modas de viola que fizeram sucesso no momento épico de crepúsculo do Brasil rural.

No último tópico, procurei mostrar como a sincopa (a irregularidade no primeiro tempo do processo histórico em questão) começou antes mesmo da grande mudança demográfica no cenário brasileiro, através da implantação de leis e medidas políticas que dificultaram a permanência do camponês no meio rural empurrando-o para a cidade. Além disso, também procurei mostrar como que, mesmo dentro deste período de mudança demográfica (compreendido entre as décadas de 1960 e 1980) houve um momento de sincopação logo no início do processo, quando na década de 1960 o camponês que havia migrado passou a sonhar com a volta para o campo e as músicas da época refletiam esta aspiração. No entanto, como foi visto, o sonho durou pouco - talvez o tempo suficiente para convencer o camponês que o êxodo para a cidade era irreversível.

Já no tópico anterior a este, procurei mostrar como a sincopa fez parte também da leitura que o camponês e seus intérpretes tinham deste processo de transformação social nas narrativas das modas de viola. O imperativo da modernidade exigia a adaptação do camponês ao ethos da nova economia e várias modas de viola apresentaram propostas de conciliação entre a tradição e a modernidade sendo algumas mais convincentes que outras ao transpor os valores da nova economia para personagens esteticamente ligados à cultura do caipira. No entanto, esses casos de sucesso foram intercalados por irregularidades já que outras modas revelavam as perdas e as tensões inerentes a este processo de transformação social bem como os limites das promessas e tentativas de conciliação entre os valores tradicionais e a modernidade. Assim, se os casos de sucesso 
eram o tempo forte, ele se fez deslocado desde o início pela ambiguidade desta adaptação manifesto pelas outras modas.

E a partir do que foi exposto no primeiro tópico deste artigo pode-se deduzir que a sincopa histórica e a sincopa temática não ocorrem desconectadas com a estética musical através da qual esta história revisitada ou "vista debaixo" a contrapelo (Benjamin, 1994, p. 225) foi registrada para a posteridade, pois a moda de viola (ao menos muitas daquelas que foram gravadas pela dupla Tião Carreiro e Pardinho) também possui a sincopa como parte integrante da sua estética. Não necessariamente na parte cantada que Rafael Garcia chamou de canto recitativo e que é marcado por outras irregularidades ainda maiores do que o desenho musical da sincopa, mas, na sua introdução como se estivesse, de alguma forma preparando o leitor para a exposição da sincopa temática que será exposta a seguir.

Até onde pude pesquisar, a moda de viola só existe no Brasil na forma como a conhecemos embora seja uma pretensão desnecessária assumir que outros países e culturas não tiveram uma forma literária musical e popular semelhante baseada em narrativas. Possivelmente o tiveram assim como também devem ter passado por processos igualmente sincopados de modernização donde se deduz que talvez a regularidade talvez não seja a regra geral. A base factual desta afirmação decorre das perspectivas metodológicas que usei na minha pesquisa de doutorado e que pertence a Raymond Williams.

Williams afirmara que um processo histórico de transformação social compreende três diferentes aspectos: o residual, o dominante e o emergente. No contexto da pesquisa em questão, pode-se dizer que, em linhas gerais, o aspecto dominante correspondia ao sistema capitalista que, em decorrência do desenvolvimento da modernidade, estendia sua racionalidade como imperativo para as diferentes esferas da realidade social. 
Já o aspecto residual correspondia às referências estéticas e temáticas de personagens e histórias típicas do universo rural como os bois, os boiadeiros, o lavrador e os violeiros. Assim, a música da modernidade começava, por assim dizer, sempre fora do tempo e da métrica de uma pretensa racionalidade porque ela dependia e se amparava na mediação de instrumentos e referências simbólicas de uma formação anterior. Porém, se esses dois elementos fazem parte de toda sociedade em transformação como pensava Williams, então este tipo de sincopa não é necessariamente uma especificidade da sociedade brasileira, mas, um princípio potencialmente universal.

Ainda segundo Williams, da combinação do residual com o dominante surge o emergente que corresponde ao novo que o período de transformação social é capaz de gerar e que no contexto analisado na minha pesquisa de doutorado equivale à criação de um ethos específico que contribuiu para o desenvolvimento do capitalismo no estado de São Paulo. E como foi aqui apresentado, este esforço de conciliação e o ethos que ele potencialmente gerou contribuiu para criar o convencimento que a realização e o sucesso no novo contexto econômico não eram uma questão meramente de sobrevivência, mas, sobretudo de conquista da honra e da dignidade a que aspira todo ser humano - valores próprios de uma formação tradicional e, portanto, caros para a população de origem camponesa.

Devido a este último aspecto, essas modas não podem ser compreendias meramente sob esta "função social" que exerceram, pois, além da realidade social que elas registraram e denunciaram, existe, em suas narrativas, elementos universais que potencialmente são capazes de tocar e sensibilizar também membros de outas culturas sendo este, a propósito, o novo horizonte de pesquisa que inicia-se este ano dentro de um intercâmbio com o King's College de Londres com o objetivo de analisar os universais presentes nas narrativas das modas de viola. 


\section{Conclusões}

Como mencionado no início deste artigo, o objetivo principal aqui foi o de verificar em que medida a sincopa, que caracterizava potencialmente a música popular brasileira, refletia uma outra sincopa que seria, esta última, constitutiva da própria sociedade brasileira criando, assim, uma espécie de unidade estética entre forma e conteúdo onde tanto a música em si quanto sua letra expressariam certo "desvio na ordem normal" que caracteriza a sincopa.

Como vimos aqui, dentro do contexto da nossa pesquisa de doutorado, à sincopa musical da moda de viola se somava a sincopa temática e a sincopação histórica. Assim, indo de um contexto mais geral para um mais específico: temos que a sincopação do processo histórico do êxodo rural brasileiro influiu sobre as narrativas que expressavam as tentativas de conciliar o moderno com o tradicional que, por sua vez, era antecipado, no canto das modas, pela sincopa presente na sua introdução e que correspondia a um novo ritmo musical: o pagode da viola.

O pagode da viola, no entanto, não era apenas um ritmo. Ele era também um novo gênero (ou subgênero) musical que passou a integrar a música caipira em geral a partir, sobretudo, das gravações da dupla Tião Carreiro e Pardinho a quem foi, inclusive, conferida sua invenção embora existam hipóteses contrária a isto. De qualquer maneira, o pagode que passou a ser uma quase exclusividade desta dupla na época era um subgênero musical diferente da moda de viola apesar dele, enquanto ritmo, se fazer presente em algumas introduções de modas de viola interpretadas pela dupla me questão.

Fora deste contexto, o pagode de viola poderia ser compreendido como a negação da moda de viola já que sua letra é a negação da narrativa e da melodia como características essenciais. Isto sugere, portanto, uma ressalva importante a ser feita sobre 
a hipótese exercitada neste artigo: a de que a sincopa da moda de viola refletiria a sincopa do processo histórico com o qual ela dialogava e retratava. Esta hipótese se aplica somente ao recorte histórico e temático realizado na minha pesquisa de doutorado, isto é, somente as modas de viola gravadas pela dupla Tião Carreiro e Pardinho. Fora deste contexto, não se pode falar de uma sincopa na moda de viola até mesmo porque o pagode ainda não havia sido criado, por assim dizer.

Em suma: no contexto da pesquisa em questão, pode-se dizer que houve um período histórico específico em que a sincopa entrou de maneira constitutiva na moda de viola. Um período em que a realidade do seu público ouvinte (o caipira) também era marcada pela sincopa, assim como seu desejo de integrar-se à modernidade. Neste período, o que o caipira teve foi, como o título deste artigo sugere, uma modernidade sincopada.

\section{Referências}

Andrade, Mário de. Dicionário musical brasileiro. Brasília, Belo Horizonte: Ministério da Cultura: Itatiaia, 1989.

Arruda, Maria Arminda do Nascimento. Metrópole e cultura: São Paulo no meio do século XX. Bauru (SP): EDUSC, 2001.

Benjamin, Walter. Magia e técnica, arte e política: ensaios sobre literatura e história da cultura. Tradução Sergio Paulo Rouanet. 1 ed. São Paulo: Brasiliense, 1994. - (Obras Escolhidas; v.1).

. Rua de mão única. Tradução Rubens Rodrigues Torres Filho e José Carlos Martins Barbosa. São Paulo: Brasiliense, 1987. - (Obras Escolhidas; v.2)

Brandão, Carlos Rodrigues. Os caipiras de São Paulo. São Paulo: Brasiliense, 1983. (Coleção tudo é história, 75). 
. O trabalho como festa: algumas imagens e palavras sobre o trabalho camponês acompanhado de canto e festa. In: Godoi, Emilia Pietrafesa; Menezes, Marilda Aparecida de; Marín, Rosa Acevedo (orgs.). Diversidade do campesinato: expressões $e$ categorias: construções identitárias e sociabilidades, v.1. São Paulo: Editora UNESP; Brasília, DF: Núcleo de Estudos e Desenvolvimento Rural, 2009, p. 39-55. (História social do campesinato brasileiro).

Cancian, Nadir Apparecida. Cafeicultura paranaense, 1900/1970. Curitiba: GRAFIPAR, 1981.

Candido, Antonio. Os parceiros do Rio Bonito: estudo sobre o caipira paulista e a transformação dos seus meios de vida. 4.ed. São Paulo: Livraria Duas Cidades Ltda., 1977.

Cano, Wilson. Ensaios sobre a crise urbana do Brasil. Campinas, SP: Editora da Unicamp, 2011.

Costa, Emília Viotti da. Da monarquia à república: momentos decisivos. 6 ed. São Paulo: Fundação Editora da UNESP, 1999. (Biblioteca básica)

Durhan, Eunice. A caminho da cidade: a vida rural e a migração para São Paulo. São Paulo: Perspectiva, 1973.

Faro, Fernando. Ensaio: Tonico e Tinoco (1997). [filme]. Produção da TV Cultura Fundação Padre Anchieta, direção de Fernando Faro. Barueri (SP), Intercd Gravações e Edições Musicais, 2007. 1 DVD ALL-NTSC, 59 min. color. son. dvd.

Faustino, Jean Carlo. A moda de viola enquanto literatura: a quintessência da sabedoria caipira. In: Souza, Marly Gondim Cavalcanti; Silva, Agnaldo Rodrigues da (org.). Diálogo entre literatura e outras artes. Cáceres, MT: Ed. UNEMAT, 2014. p. 121-136.

- A moda de viola enquanto literatura. In: SILVA, Agnaldo Rodrigues da (org.). Escritos culturais: literatura, arte e movimento. Cáceres: Ed. UNEMAT; Editora de Liz, 2011. p. 153-170.

. O Êxodo Cantado: a formação do caipira para a modernidade. 2014. 196p. Tese (Doutorado em Sociologia) - Departamento de Sociologia. Universidade Federal de São Carlos (UFSCar), São Carlos (SP), 2014. 
Freitas, Sérgio Paulo Ribeiro de. A memória e o valor da síncope: da diferença do que ensinam os antigos e os modernos. Belo Horizonte: Per musi, n. 22, julho/dezembro de 2010.

Garcia, Rafael Marin da Silva. Moda-de-viola: lirismo, circunstancia e musicalidade no canto recitativo caipira. 2011. 335p. Dissertação (Mestrado em Música) - Instituto de Artes. Universidade Estadual Paulista, São Paulo, 2011.

Gonzales, Elbio N.; Bastos, Maria Ines. O trabalhador volante na agricultura brasileira. In: Pinsky, Jaime (org.) Capital e trabalho no campo. São Paulo: HUCITEC, 1979, p. 25-47. (Coleção estudos brasileiros, 7)

Gumboski, Leandro. O gênio, por Jean-Jacques Rousseau (1712-1778): tradução e alguns comentários histórico-analíticos. Ouro Preto: Artefilosofia, n. 13, p.196-211, dezembro de 2012.

Martín-Barbero, Jesús. Dos meios às mediações: comunicação, cultura e hegemonia. Tradução de Ronald Polito e Sérgio Alcides. 2. ed. Rio de Janeiro: Editora UFRJ, 2001.

Martins, José de Souza. Conde Matarazzo: o empresário e a empresa: estudo de sociologia do desenvolvimento. 2. ed. São Paulo: HUCITEC, 1974. (Coleção estudos brasileiros, 1).

- Música Sertaneja: a dissimulação na linguagem dos Humilhados. In:

Martins, José de Souza. Capitalismo e tradicionalismo. São Paulo: Livraria Pioneira Editora, 1975. p. 103-161.

Marx, Karl. O Capital: crítica da economia política. Tradução de Regis Barbosa e Flávio R. Kothe. São Paulo: Nova Cultural, 1996. Livro 1, v.1, t.1. (Os economistas).

Menezes, Eduardo de Almeida. Moda de viola e modos de vida: as representações do rural na moda de viola. 2008. 196p. Dissertação (Mestrado em Ciências Sociais em Desenvolvimento, Agricultura e Sociedade) - Instituto de Ciências Humanas e Sociais. Universidade Federal Rural do Rio de Janeiro, Rio de Janeiro, 2008.

Nepomuceno, Rosa. Música caipira: da roça ao rodeio. 1.ed. São Paulo: Editora 34, 1999. 
Oliveira, Allan de Paula. O tronco da roseira: uma antropologia da viola caipira. 2004. 178p. Dissertação (Mestrado em Antropologia Social) - Programa de Pós-Graduação em Antropologia Social. Universidade Federal de Santa Catarina, Florianópolis, 2004.

Ortiz, Renato. Cultura brasileira \& identidade nacional. São Paulo: editora Brasiliense, 1985.

Payes, Manuel Antonio Munguia. O norte do Paraná: expansão cafeeira e apropriação da renda fundiária desde fins do século XIX até 1960. 1984. 173p. Dissertação (Mestrado em Desenvolvimento Agrícola) - Instituto de Ciências Humanas e Sociais. Universidade Federal Rural do Rio de Janeiro, Itaguaí, 1984.

Pimentel, Sidney Valadares. O chão é o limite: a festa do peão de boiadeiro e a domesticação do sertão. 1ed. Goiânia: Editora UFG, 1997.

Pinto, Ivan Vilela. Cantando a própria história. 2011. 195p. Tese (Doutorado em Psicologia Social) - Departamento de Psicologia Social. Universidade de São Paulo, São Paulo, 2011.

Pinto, João Paulo do Amaral. A viola caipira de Tião Carreiro. 2008. 291p. Dissertação (Mestrado em Música) - Programa de Pós-graduação do Instituto de Artes. Universidade Estadual de Campinas, Campinas, 2008.

Sandroni, Carlos. Feitiço Decente: transformações do samba no Rio de Janeiro (19171933). Rio de Janeiro: Jorge Zahar Editor Ltda, 2012.

Silva, José Graziano da. Progresso técnico e relações de trabalho na agricultura. São Paulo: Editora HUCITEC, 1981.

Silva, Maria Aparecida de Moraes. Errantes do fim do século. São Paulo: Fundação Editora da UNESP, 1999.

Sobral, Lina Ribeiro. O trabalhador rural brasileiro no café: ideologia e identidade (1920/30). 1992. 151p. Dissertação (Mestrado em História) - Curso de Mestrado em História. Pontifícia Universidade Católica de São Paulo, São Paulo, 1992.

Souza, Cristiane Rodrigues de. Mário de Andrade: o sequestro do desejo e a música popular em versos. São Paulo: Revista do Instituto de Estudos Brasileiros, n.57, dezembro de 2013. 
Stolcke, Verena. Cafeicultura: homens, mulheres e capital (1850-1980). Tradução de Denise Bottmann e João R. Martins Filho. São Paulo: Brasiliense, 1986.

Vilela, Ivan. O caipira e a viola brasileira. In: Pais, José Machado; Brito, Joaquim Pais de; Carvalho, Mário Vieira de (orgs.). Sonoridades luso-afro-brasileiras. Cap. X. Lisboa: Imprensa de Ciências Sociais, 2004, p.171-187.

Weber, Max. A ética protestante e o espírito do capitalismo. Tradução: Pietro Nassetti. São Paulo: Martin Claret, 2001.

Weber, Max. História geral da economia. Tradução de Calógeras A. Pajuaba. São Paulo: Mestre Jou, 1968. p. 308-322.

Williams, Raymond. Marxismo e literatura. Tradução de Waltensir Dutra. Rio de Janeiro: Zahar Editores, 1979.

Willems, Emilio. Cunha: tradição e transição em uma cultura rural do Brasil. São Paulo: Secretaria da Agricultura do Estado de São Paulo, Diretoria de Publicidade Agrícola, 1947. 